\title{
ЖИЛИЩНЫЙ ВОПРОС ВНУТРЕННЕ ПЕРЕМЕЩЕННЫХ ЛИЦ В УКРАИНЕ
}

\section{Татьяна ГНАТЮК ${ }^{\odot}$, кандидат политических наук, старший научный сотрудник,} Институт демографии и социальных исследований имени М.В. Птухи, Национальная академия наук Украины

DOI: $\underline{\text { https://doi.org/10.36004/nier.cdr.2019.14-05 }}$ JEL Classification: I70, J15.

В статье автор раскрывает ситуаџию с решением жсилищного вопроса внутренне перемещенных лии в Украине. По прошествии более пяти лет с момента появления этой категории лии, обеспечение их постоянным жильем остается все так же актуальным. Целью данной статья является оценка ситуаџии в сфере жилья для внутренне перемещенных лич. Автором проанализировано отчеты Национальной системы мониторинга ситуачии с внутренне перемещенными лицами, отчеты международных организащий, а также соответствующяая законодательная база Украины. Автор приходит $\kappa$ выводу, что предоставляемая украинским государством помощь является малоэффективной. Существующие международные проекты не могут в полной мере обеспечить жильем всех нуждающихся переселенцев. Таким образом, внутренне перемещенные лииа в Украине решают жилищную проблему преимущественно самостоятельно.

Ключевые слова: внутренне перемещуенные лища, жилищный вопрос, виды жилья, модульные городки, сочиальное жилье, Украина.

In the article, the author describes the situation on accommodation of the internally displaced persons in Ukraine. After more than five years since the appearance of this category of people, providing them with permanent housing has remained extremely important. The purpose of this article is to assess the housing situation for internally displaced persons. The author has analyzed the reports of the National monitoring system on the situation of internally displaced persons, reports of international organizations, as well as the relevant legislation of Ukraine. The author has concluded that the assistance provided by the Ukrainian state is ineffective. Existing international projects cannot fully provide housing for all displaced persons in need. Thus, internally displaced persons in Ukraine solve the housing problem mainly on their own.

Key words: internally displaced persons, housing problem, types of housing, modular towns, social housing, Ukraine.

Внутренне перемещенные лица (ВПЛ) появились в Украине с марта 2014 года в связи c аннексией Российской Федерацией Автономной Республики Крым. Начало военного конфликта на территории Донецкой и Луганской областей Украины в мае 2014 года усилило внутреннее перемещение. По состоянию на конец августа 2019 года [7] на учете Министерства социальной политики Украины находилось 1,4 млн. внутренне перемещенных лиц.

С момента начала перемещения жилищная проблема является одной из основных (наряду с трудоустройством) для данной категории внутренних мигрантов в Украине. За последние пять лет украинским государством и международными организациями предпринимались определенные шаги для решения этого вопроса. Тем не менее, за данными Международной организации по миграции [21, с. 22], в марте этого года лишь 14\% ВПЛ проживало в собственном жилье.

\footnotetext{
๑ Татьяна Гнатюк, tetyana_hnatyuk@bigmir.net
} 
Целью данной статья является оценка ситуации в сфере жилья для внутренне перемещенных лиц спустя пять лет после возникновения процесса внутреннего перемещения в Украине.

Для обеспечения поставленной цели автором проанализировано отчеты Национальной системы мониторинга ситуации с внутренне перемещенными лицами за три года (с марта 2016 г. по март 2019 г.), отчеты Управления Верховного Комиссара ООН по делам беженцев (УВКБ ООН), Международной организации по миграции (МОМ), а также законодательная база Украины, касающиеся жилищной проблемы ВПЛ.

Украинское государство не было готово к появлению внутренне перемещенных лиц в 2014 году. Таким образом, первое время расселение носило стихийный характер [16, с. 193]: переселенцы получали кров в государственных санаториях, домах отдыха, церквях, в частном секторе или у родственников; также временное жилье предоставляли владельцы частных отелей и местная власть. Учитывая ситуацию, в которой решался вопрос о срочном обеспечении переселенцев крышей над головой, качество жилья отошло на второй план. В результате, ВПЛ часто селили в неприспособленных для долгосрочного жилья помещениях, а также в сельской местности с ограниченным доступом к рабочим местам.

Проведенная УВКБ ООН в 2015 году оценка потребностей ВПЛ в Киевской [22, с. 3] и Луганской [23, с. 18] областях подтвердила сложившуюся ситуацию. Опрошенные жаловались на отсутствие постоянного жилья, удаленное расположение, предубежденность арендодателей и высокие цены на аренду, а также нехватку мест в центрах коллективного проживания ВПЛ.

В октябре 2014 года был принят Закон Украины «Об обеспечении прав и свобод внутренне перемещенных лиц» [10], определяющий среди прочего предоставление государством помощи ВПЛ в решении жилищной проблемы. В соответствии со статей 9 Закона внутренне перемещенное лицо имеет право на:

- $\quad$ создание условий для его постоянного или временного проживания;

- оплату стоимости коммунальных услуг, электрической и тепловой энергии, природного газа в местах компактного поселения внутренне перемещенных лиц (городках из сборных модулей, общежитиях, оздоровительных лагерях, домах отдыха, санаториях, пансионатах, гостиницах и т.д.) по соответствующим тарифам, установленным на такие услуги и товары для населения;

- $\quad$ обеспечения органами государственной власти, органами местного самоуправления и субъектами частного права возможности бесплатного временного проживания (при условии оплаты лицом стоимости коммунальных услуг) в течение шести месяцев с момента постановки на учет внутренне перемещенного лица; для многодетных семей, лиц с инвалидностью, пожилых людей этот срок может быть продлен.

Таким образом, Закон предусматривает предоставление бесплатного временного жилья ВПЛ только на полгода с момента их регистрации. Исключения предполагаются для особо уязвимых категорий: инвалидов, многодетных семей и пожилых людей.

Также в октябре 2014 года Правительством Украины было издано Постановление «О предоставлении ежемесячной адресной помощи внутренне перемещенным лицам для покрытия расходов на проживание, в том числе на оплату жилищно-коммунальных услуг» [12], предусматривающее выплаты на срок не более чем полгода с момента обращения ВПЛ, а также определяющее размер выплат. По состоянию на 14 августа 2019 г., суммы выплат были следующие:

- $\quad$ для трудоспособного лица - 442 гривны $\left(17,6\right.$ долларов США $\left.{ }^{15}\right)$,

- $\quad$ для пенсионеров и детей - 1000 гривен (39,8 долларов США),

\footnotetext{
15 Для расчета взят официальный курс гривны по отношению к доллару США Национального банка Украины (на 14 августа 2019 г.): 25,15 гривен за 1 доллар США [9].
} 
- для людей с инвалидностью - от одного прожиточного минимума до 130\% прожиточного минимума (в зависимости от группы инвалидности).

При этом сумма на семью не может превышать 3000 гривен (119,3 долларов США), для семьи с инвалидами - не более 3400 гривен (135,2 долларов США), для многодетных семей - не более 5000 гривен (198,8 долларов США).

Приведем для сравнения цены на аренду однокомнатных квартиры в регионах основного скопления переселенцев (на декабрь 2018 г.) [8]: Донецкая область - 2145 гривен; Луганская область - 1783 гривны; г. Киев - 6636 гривен; Харьковская область - 3447 гривен; Днепропетровская область - 2452 гривны; Киевская область - 2906 гривен. Таким образом, выплачиваемая внутренне перемещенным лицам помощь государства является недостаточной для покрытия расходов на аренду квартиры и оплату коммунальных услуг.

С марта 2016 года МОМ инициировала проведение Национальной системы мониторинга ситуации с внутренне перемещенными лицами в Украине, которая уже насчитывает 13 раундов. В перечень освещаемых тем входят условия проживания и виды жилья ВПЛ. Существующая система мониторинга позволяет увидеть изменения, произошедшие в ситуации с жильем переселенцев за последние три года (Таблица 1.).

Таблица 1. Вид жилья, в котором проживают внутренне перемещенные лица, \%

\begin{tabular}{|c|c|c|c|c|c|c|c|c|c|c|c|c|}
\hline $\begin{array}{c}\text { Вид жилья } \\
\text { ВПЛ }\end{array}$ & 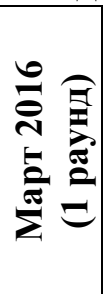 & 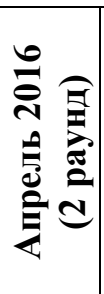 & 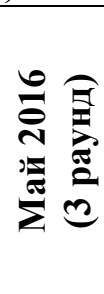 & 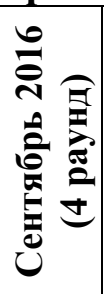 & 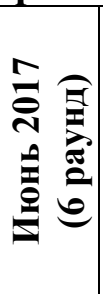 & 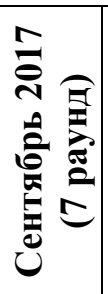 & 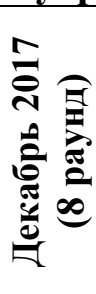 & 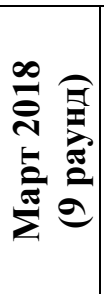 & 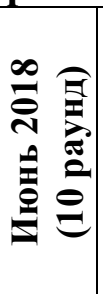 & 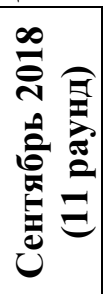 & 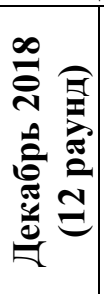 & 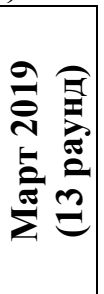 \\
\hline $\begin{array}{l}\text { Собственное } \\
\text { жилье }\end{array}$ & $\cdots$ & $\ldots$ & $\ldots$ & 4,0 & 9,0 & 10,0 & 11,0 & 12,0 & 12,0 & 15,0 & 12,0 & 14,0 \\
\hline $\begin{array}{l}\text { Аренда } \\
\text { квартиры }\end{array}$ & 35,3 & 42,0 & 47,0 & 40,0 & 46,0 & 49,0 & 47,0 & 47,0 & 48,0 & 45,0 & 49,0 & 49,0 \\
\hline Аренда комнаты & 8,1 & 6,0 & 7,0 & 7,0 & 4,0 & 4,0 & 3,0 & 5,0 & 4,0 & 4,0 & 4,0 & 4,0 \\
\hline Аренда дома & 13,4 & 20,0 & 15,0 & 15,0 & 8,0 & 6,0 & 8,0 & 9,0 & 10,0 & 10,0 & 10,0 & 9,0 \\
\hline $\begin{array}{l}\text { Принимающая } \\
\text { семья/ } \\
\text { родственники }\end{array}$ & 18,8 & 22,0 & 20,0 & 25,0 & 26,0 & 25,0 & 24,0 & 13,0 & 13,0 & 14,0 & 14,0 & 13,0 \\
\hline Общежитие & 12,7 & 6,0 & 7,0 & 6,0 & 3,0 & 3,0 & 3,0 & 7,0 & 5,0 & 4,0 & 4,0 & 5,0 \\
\hline $\begin{array}{l}\text { Центры } \\
\text { коллективного } \\
\text { проживания } \\
\text { ВПЛ }\end{array}$ & 8,7 & 1,0 & 2,0 & 2,0 & 2,0 & 1,0 & 1,0 & 4,0 & 4,0 & 4,0 & 3,0 & 3,0 \\
\hline Другое & 3,0 & 3,0 & 2,0 & 1,0 & 2,0 & 2,0 & 3,0 & 3,0 & 4,0 & 4,0 & 4,0 & 3,0 \\
\hline
\end{tabular}

Источник: Отчеты Национальной системы мониторинга ситуации с ВПЛ, 2016-2019 гг. [17, 18, 19, 20, 21]

Исходя из результатов 13-ти раундов Национальной системы мониторинга, больше половины опрошенных ВПЛ арендуют жилье, и процент таких переселенцев за период обследования увеличился: с 56,8\% в марте 2016 г. до 62,0\% в марте 2019 г. Арендуемая квартира остается самым популярным видом жилья ВПЛ. Если в начале 2016 года квартиру арендовали $35,3 \%$ опрошенных, то за последующие три года их количество достигло почти половины всех респондентов. При этом за период проведения мониторинга практически вдвое сократился процент ВПЛ, арендующих комнату или дом.

Не смотря на высокий процент переселенцев, арендующих жилье, аренда является серьезной нагрузкой на семейный бюджет даже работающих ВПЛ [15, с. 45]. Кроме того, ВПЛ отмечают неравное отношение к ним арендодателей [2, с. 27]: завышенные цены по 
сравнению с ценами для местного населения; нежелание арендодателей заключать долгосрочные контракты с переселенцами, что лишает последних права на получение субсидий от государства на оплату коммунальных услуг; выселение в летнее время с помещений в курортных зонах, так как арендодатели практикуют сдачу жилья посуточно в летние месяцы.

По результатам последнего раунда Национальной системы мониторинга в марте 2019 года $14 \%$ опрошенных ВПЛ заявили, что проживают в собственном жилье. При этом наблюдается увеличения показателя в три с половиной раза по сравнению с сентябрем 2016 года (Таблица 1.).

Украинское государство внесло переселенцев в число категорий лиц, имеющих право участвовать в Государственной программе «Доступное жилье» [1]. Прием заявок от ВПЛ стартовал с конца ноября 2017 года. Реализация Программы осуществляется Государственным специализированным финансовым учреждением «Государственный фонд содействия молодежному жилищному строительству». По условиям Программы [3], участникам-переселенцам предоставляется государственная помощь в размере $50 \%$ стоимости строительства (приобретения) доступного жилья и/или льготный ипотечный кредит. Программа имеет ряд ограничений, среди которых: приобретаться должно только первичное жилье; предусмотрен определенный список застройщиков; определена граничная жилплощадь на одного члена семьи; установлены ограничения на стоимость 1 м $^{2}$ жилья, которое оплачивает государство. Кроме этого, установлены довольно сжатые сроки внесения 50\% стоимости жилья со стороны ВПЛ: в течение 15 дней с момента подписания договора.

УВКБ ООН провело оценку [14] Программы «Доступное жилье» с точки зрения семей, получивших жилье в рамках Программы в 2017 году. Анализ показал, что принявшие участие домохозяйства ВПЛ имеют значительно более высокий уровень дохода, чем домохозяйства переселенцев в среднем по Украине: зарплата является основным источником дохода для 76\% опрошенных; большинство семей имеют несколько источников дохода; $63 \%$ опрошенных использовали личный накопления для выплаты $50 \%$ стоимости жилья (30\% использовали частный заем). Таким образом, в рамках Программы получить поддержку от государства в приобретении жилья могут только состоятельные ВПЛ.

Проживание с принимающей стороной или родственниками является популярным вариантом среди переселенцев. По данным Национальной системы мониторинга, практически каждый четвертый респондент в период с сентября 2016 г. по декабрь 2017 г. сообщил о таком виде жилья. Тем не менее, к марту 2019 года процент таких ВПЛ снизился вдвое и составил $13,0 \%$ среди всех опрошенных.

Незначительная часть ВПЛ проживает также в общежитиях и центрах коллективного проживания. Однако, по данным Национальной системы мониторинга, процент переселенцев за последние три года почти вдвое сократился в этих видах жилья. Такое положение дел объясняется, во-первых, временностью данного жилья, а во-вторых, неудовлетворительными условиями проживания.

Не смотря на то, что принятая в декабре 2015 года Комплексная государственная программа поддержки ВПЛ [11] предполагала мероприятия по обеспечению права переселенцев на жилье (создание социального жилищного фонда для передачи в аренду ВПЛ на льготных условиях, реализация проектов постройки специализированных социальных поселков, строительство коттеджных городков для переселенцев и т.д), фактически строительство временного жилья для переселенцев осуществлялось международными инвесторами. В частности, семь модульных городков (в Харькове, Запорожье, Павлограде, Кривом Роге, Никополе, Каменском и Днепре) были построены на деньги Немецкого правительства в начале 2015 года с термином эксплуатации до середины 2017 года [5].

Необходимо отметить, что для большинства ВПЛ временное проживание в модульных городках стало постоянным, так как в них размещаются самые уязвимые 
категории, не имеющие возможности переехать. Не смотря на ухудшение условий проживания в результате окончания срока эксплуатации, покидать жилье переселенцы не намерены. Социальный климат в городках зависит от наличия финансовой поддержки местной власти. Например, модульный городок в г. Днепр финансируется из бюджетов города и области, и соответственно переселенцы вносят за свое проживание символическую плату (150 гривен с человека в месяц) [13]. Совершенно другая ситуация сложилась в модульном городке в Павлограде: после поднятия тарифов на коммунальные услуги в три раза и прекращения дотаций, часть переселенцев выехала, оставив долги [4].

Експерты отмечают [5], что в целом для модульных городков характерны следующие проблемы: отсутствие интеграции в местные общины, пьянство, наркомания, бытовые конфликты, зависимость от гуманитарной помощи, нежелание работать. Сами ВПЛ, проживающие в местах компактного проживания, жалуются на необоснованные меры ограничения со стороны администрации некоторых городков, страх быть принудительно выселенными, отсутствие личного пространства, нехватку специального оборудования или отсутствие условий для людей с инвалидностью [2, с. 26]. Таким образом, компактное размещение переселенцев не может рассматриваться как приемлемое долгосрочное решение.

Правительство Германии также финансирует строительство социального жилья для ВПЛ. В рамках проекта «Содействие развитию социальной инфраструктуры. Украинский фонд социальных инвестиций $\mathrm{V} \gg$ проводится капитальный ремонт зданий, находящихся в коммунальной собственности общин, для создания в них жилья для переселенцев. Проект реализуется в Киеве, Львове, Харьковской, Днепропетровской и Запорожской областях. На пример, в Харьковской области социальное жилье для ВПЛ обустроено в шести городах (Золочев, Дергачи, Изюм, Красноград, Лозовое, Богодухов). Это 16 квартир и 99 комнат в общежитиях, рассчитанных на 300 человек, а также семь объектов инфраструктуры [6].

Выводы. Спустя почти шесть лет с момента появления внутренне перемещенных лиц в Украине, ситуация с обеспечением жильем данной категории украинских граждан остается нерешенной. Помощь украинского государства носит преимущественно временный характер и является малоэффективной. Конкретные шаги для решения жилищного вопроса ВПЛ осуществляются международными организациями за счет иностранных доноров. Тем не менее, существующие международные проекты не могут в полной мере обеспечить жильем полтора миллиона переселенцев. В результате большинство внутренне перемещенных лиц рассчитывает в этом вопросе только на себя.

1. Житлова програма «Доступне житло». Державний фонд сприяння молодіжному житловому будівництву. https://www.molod-kredit.gov.ua/zhytlovi-prohramy/dostupne-zhytlo.

2. Звіт про результати спільної оцінки потреб біженців, шукачів притулку, внутрішньо переміщених осіб та осіб без громадянства в Україні. УВКБ ООН. Київ, 2019, 31 с. https://www.unhcr.org/ua/wp-content/uploads/sites/38/2019/08/2019-08-19-PA_UKR.pdf.

3. Ссіна Н. Як працює програма «Доступне житло» для ВПО. Ресурсний центр ГУРТ. 04.01.2018. https://gurt.org.ua/news/informator/42728/bull/.

4. Колмогоров С. Модульні містечка для переселенців: Місію виконано, але крапку не поставлено. Depo.ua. 6 березня 2019 p. https://dnipro.depo.ua/ukr/dnipro/modulni-mistechka-dlyapereselentsiv-misiyu-vikonano-ale-krapku-ne-postavleno-20190306926816.

5. Модульні містечка для переселенців з Донбасу перетворюються на «депресивні гетто» $\begin{array}{lllllll}\text { журналісти. Інформаційне } & \text { агентство } & \text { УНІАН. } & 9 & \text { серпня } & 2018 .\end{array}$ https://www.unian.ua/society/10218782-modulni-mistechka-dlya-pereselenciv-z-donbasuperetvoryuyutsya-na-depresivni-getto-zhurnalisti.html. 
6. На Харьковщине восстановленное жилье получат 300 переселенцев из Донбасса. Depo.ua. 20 червня 2019 p. https://kh.depo.ua/rus/kh/na-kharkivshchini-vidnovlene-zhitlo-otrimayut300-pereselentsiv-iz-donbasu-20190620982150.

7. Обліковано 1402869 внутрішньо переміщених осіб. Міністерство соціальної політики України. 27.08.2019. https://www.msp.gov.ua/news/17509.html.

8. Оренда житла в Україні: де найдешевше та найдорожче (інфографіка). Finance.ua. 21 березня 2019 p. https://news.finance.ua/ua/news/-/446009/orenda-zhytla-v-ukrayini-de-najdeshevshe-inajdorozhche-infografika.

9. Офіціальний курс гривні щодо іноземних валют. Національний банк України. 14 серпня 2019 p. https://bank.gov.ua/markets/exchangerates/?date=14.08.2019\&period=daily.

10. Про забезпечення прав і свобод внутрішньо переміщених осіб. Закон України № 1706-VII від 20 жовтня 2014 p. Верховна Рада України. https://zakon5.rada.gov.ua/laws/show/1706-18.

11. Про затвердження Комплексної державної програми щодо підтримки, соціальної адаптації та реінтеграції громадян України, які переселилися з тимчасово окупованої території України та районів проведення антитерористичної операції в інші регіони України, на період до 2017 року. Постанова Кабінету Міністрів України від 16 грудня 2015 р. № 1094. https://zakon.rada.gov.ua/laws/show/1094-2015-\%D0\%BF\#n10.

12. Про надання щомісячної адресної допомоги внутрішньо переміщеним особам для покриття витрат на проживання, в тому числі на оплату житлово-комунальних послуг. Постанова Кабінету Міністрів України № 505 від 1 жовтня 2014 р. Верховна Рада України. https://zakon.rada.gov.ua/laws/show/505-2014-\%D0\%BF.

13. Рацибарська Ю. Модульні містечка для переселенців: чому з одного тікають, а в інші черги. Радіо Свобода. 13 червня 2019 p. https://www.radiosvoboda.org/a/29819569.html.

14. Участь ВПО за програмою «Доступне житло» (50/50). Звіт за результатами оцінювання. УВКБ ООН. 23.01.2019. https://www.unhcr.org/ua/wp-content/uploads/sites/38/2019/02/2019UNHCR-Evaluation-of-State-Youth-Fund-Housing-Programme-Final-Report.UKR .pdf.

15. Desk Research of the Surveys of IDPs. GfK. Kyiv, December 2017, $53 \mathrm{c}$. https://www.unhcr.org/ua/wp-content/uploads/sites/38/2018/05/gfk_unhcr_desk_report_final.pdf.

16. Hnatyuk T.O. Internally Displaced Persons: A New Challenge for Ukraine. Демографія та соціальна економіка, 2014, № 2 (22), C. 187-197. DOI 10.15407/dse2014.02.187.

17. National Monitoring System of the Situation with Internally Displaced Persons. Round 1. March 2016. International Organization for Migration (IOM): Mission in Ukraine. Kyiv, 2016, 14 p. http://iom.org.ua/sites/default/files/iom_nms_r1_eng.pdf.

18. National Monitoring System of the Situation with Internally Displaced Persons. Round 2. April 2016. International Organization for Migration (IOM): Mission in Ukraine. Kyiv, 2016, 22 p. http://iom.org.ua/sites/default/files/iom_nms_r2-v.pdf.

19. National Monitoring System of the Situation with Internally Displaced Persons. Round 3. May 2016. International Organization for Migration (IOM): Mission in Ukraine. Kyiv, 2016, 14 p. http://iom.org.ua/sites/default/files/iom_nms_r3_f.pdf.

20. National Monitoring System of the Situation with Internally Displaced Persons. Round 4. September 2016. International Organization for Migration (IOM): Mission in Ukraine. Kyiv, 2016, 33 p. http://iom.org.ua/sites/default/files/iom_nms.pdf.

21. National Monitoring System Report on the Situation of Internally Displaced Persons. March 2019. International Organization for Migration (IOM): Mission in Ukraine. Kyiv, 2019, 67 p. http://iom.org.ua/sites/default/files/nms_round_13_eng.pdf.

22. Participatory Assessment Report. Kyiv and Kyiv Oblast, 2015. UNHCR. The UN Refugee Agency. http://unhcr.org.ua.

23. Participatory Assessment Report. Luhansk Region, Ukraine, April 2015. UNHCR. The UN Refugee Agency. http://unhcr.org.ua. 